\title{
Effect of Plant Growth Hormones on Sprouting and Rooting Behaviour of Clones of Various Bamboo Species in coastal Odisha
}

\author{
S. Sahoo ${ }^{*}$, R. K. Kar and T. L. Mohanty \\ College of Forestry, Odisha University of Agriculture and Technology, \\ Bhubaneswar-751003, Odisha, India \\ *Corresponding author
}

\section{Keywords}

Clones, Culms, IBA, Bambusa Spp. Sprouting, Rooting

Article Info

Accepted:

22 June 2020

Available Online:

10 July 2020

\section{A B S T R A C T}

The present crisis has emphasized human dependency on bamboo with quality planting materials. A study focused on the effect of the different concentrations of IBA ( 0 ppm, 100 ppm, $200 \mathrm{ppm}, 300 \mathrm{ppm}$ ) on the sprouting and rooting behaviours of 5 bamboo species viz. Dendrocalamus strictus, Bambusa vulgaris, B. nutans, B. tulda and B. bambos found in coastal Odisha in order to get an idea for mass multiplication and biomass production to meet the multifarious demands of bamboo based sector. It was carried out in Split-Plot Design with 3 replications with 5 species of bamboo as main plot factor band different concentrations of IBA as sub- plot factor. Different doses of IBA (0 ppm, 100 ppm, 200 ppm and $300 \mathrm{ppm}$ ) were prepared and those concentrations were poured inside the hole that were made with the help of a driller and then planted in prepared raised bed of $40 \times 37$ ft. After 3 months different parameters such as root length, leaf area, No. of roots, Above and underground Biomasses etc. are studied and observations were recorded. Max. no. of roots was observed in $B$. nutans for $0 \mathrm{ppm}$. Longest root length was recorded in $B$. nutans for $300 \mathrm{ppm}$. Max. fresh and dry below ground biomass was observed in B. nutans for 300 ppm and Max. Fresh and dry above ground biomass was recorded in B. nutans for 0 ppm and $300 \mathrm{ppm}$ respectively. Mas. Quality index was recorded in B. nutans for $0 \mathrm{ppm}$ and highest volume index was observed in B. vulgaris for $200 \mathrm{ppm}$.

\section{Introduction}

Bamboo, the foundation of economy of the rural poor has soared enthusiasm among the farming communities during contemporary period. It is an evergreen woody perennial and considered to be the fastest growing plants in the world (Seethalakshmi et al., 1998). India is the second richest country in bamboo, genetic resources after China. About 130 species are so far reported from India
(Sharma, 1987). The growing demand has created huge planting material in India, the future plantation of bamboos will require over 70 million plants (Haridasan et al., 2008). Odisha accounts $9 \%$ of the country's total bamboo forest cover and $7 \%$ of total growing stock of Bamboo. Bamboo although known as the "poor man's timber" in the past, due to its versatile and multifarious uses it is now being elevated to the status of the "timber of the 21 " century". Conventional propagation of 
bamboo is based on seed and vegetative methods. However, the availability of bamboo seeds is limited due to a long flowering cycle. Even if seeds are available, they have low viability and poor storage characteristics. Further, species like Bambusa vulgaris and Bambusa balcooa flower rarely, thereby making their propagation absolutely dependent on vegetative means (Naithani et al., 1992; Banik, 2000). Bamboo seeds have a short life. Vegetative propagation is complicated and can result in an undesirable narrowing of the genetic base however Tissue culture is not yet possible without seed to provide initial embryogenic callus. The propagation through rooting of culm cuttings has been found to be successful in many bamboo species and the rooting ability varies with species, some species rooting with ease whereas, some others are found difficult to root. Culm cuttings/branch cuttings offer effective, simple and useful solution for mass multiplication of bamboos (Banik, 2008; Pattanaik, 2004). However, bamboo species exhibit significant variations in the capability of adventitious rhizogenesis (Singh et al., 2006). The success of root induction culm cuttings depends on various factors such as season, node position etc. Although Bamboo is widely distributed with high species diversity in India, it is not fully exploited to meet industrial wood demand. Being a biological material, it is subjected to greater variability and complexity due to various growing conditions such as moisture, soil and competition. This study was carried out to find out the most suitable concentration of Indole Butyric Acid (IBA) for the clonal propagation of various economically important bamboo species in coastal agroclimatic conditions of Odisha with a view to develop massive plantations by farmers for economic profitability. The gap between demand and supply of bamboo is increasing daily due to the destruction of natural bamboo resources. Therefore, there is a pressing need to find suitable methods for large-scale propagation of bamboo. Currently, bamboo is propagated mainly using vegetative means since seed supplies are often variable or limited.

\section{Materials and Methods}

\section{Experimental site and climatic conditions}

The experimental site is situated in the College of Forestry Research field which is located at $20^{\circ} 16^{\prime}$ 35.6" North Latitude and $85^{\circ} 47$ ' 25.9" East Longitude with an average altitude of 55 metre (183 feet) above mean sea level (M.S.L.).It is situated near Baramunda Bus-stand at a distance of $4.5 \mathrm{Km}$ from head quarter of OUAT. The experimental field is fairly levelled and well drained. Soil is sandy loam in texture. The bulk density (BD) is $1.54 \mathrm{~g} / \mathrm{cm} 3$, Particle density (PD) is $2.65 \mathrm{~g} / \mathrm{m} 3$ and porosity is $41.9 \%$. The $\mathrm{P}^{\mathrm{H}}$ of the soil is 5.34 and electrical conductivity EC is $0.197 \mathrm{ds} / \mathrm{m}$. The study area falls under the eastern coastal plains of Odisha along the axis of the NorthEastern Ghats Mountains. The climate was relatively warm and dry with a typical effect of humid costal belt. Bhubaneswar is located on the coastal plains of Odisha. The average annual rainfall of Bhubaneswar is $1552 \mathrm{~mm}$ (based on average of preceding 10 years). Most of the rainfall i.e. $85 \%$ is received from July to September.The meteorological data recorded at Meteorological Observatory of Orissa University of Agriculture and Technology, Bhubaneswar and presented in figure 1 .

\section{Experimental material}

5 economically bamboo species of Odisha viz. were selected for the investigation. Superior 1-year culms of bamboo were collected from healthy clumps of 5 different types of bamboo species using a sharp axe 
from OUAT farm and Silvicultural research stations, Bhubaneswar for present research purpose. Different bamboo species that were used in this experiment are as follows: Dendrocalamus strictus, Bambusa vulgaris, Bambusa nutans, Bambusa tulda and Bambusa bambos. 2-3 one-year aged culms each of Bambusa bambos, Dendrocalamus strictus and Bambusa vulgaris collected from OUAT livestock farm where as each of Bambusa tulda and Bambusa nutans were collected from Silvicultural Research Stations, Bhubaneswar. The collection was done in march.

\section{Methodologies followed}

Experimental plot was ploughed and prepared using spade. The size of the plot was $40 \times 37$ sq. ft. (Fig. 2). The whole experimental plot was divided in to three blocks R1 and R2 and R3 (3 replications). Each block was subdivided in to 5 plots each representing a species. The details of the main plot are A1Dendrocalamus strictus, A2- Bambusa vulgaris, A3-Bambusa nutans, A4- Bambusa tulda, A5- Bambusa bambos. Each plot was further divided in to 4 sub-plots. 4 sub-plots represent 4 concentration of IBA i.e. B1: 0ppm, B2: 200ppm, B3: 300ppm, B4: $400 \mathrm{ppm}$. spacing was given $1 \mathrm{ft}$ from row to row. (Table.1). The culms were cut into double nodes and a square shaped hole was made in between the culms using an electrical driller so that IBA hormone can be filled inside. Bi- nodal cuttings were cut from each species of bamboo with the help of a sharp boat shaped saw. Total no. of treatment combinations was 20. Number of cuttings were 10 i.e., under each sub-plot of a plot 10 Bi-nodal cuttings were planted in one channel. In order to plant the bi-nodal culms appropriate solution of IBA $(60-70 \mathrm{ml})$ was poured inside the prepared hole (Fig.2) and it was covered with a wide piece of brown cello-tape so that the complete circumference of the hole can be covered. The culm cuttings were so prepared that it was planted in right place as per the lay out (Table1). The cuttings were planted horizontally 10-12-inch-deep from ground level with hole of the cuttings facing upwards. Channel to channel distance while planting was $1 \mathrm{ft}$. The entire plot was subjected to watering everyday with exception to extreme hot weather and shower. During extreme hot days irrigation was doubled and during rainy days it was skipped. The sprouting behaviour were recorded at 90 Days After Planting (DAP).

\section{Preparation of IBA treatment solution}

For IBA treatment of bi-nodal cuttings different concentrations i.e. 0ppm (water treatment), 100ppm, 200ppm and 300ppm, solutions were prepared.

\section{Preparation of IBA ppm concentrations}

For preparation of 100ppm, 200ppm, 300 ppm concentrations; $1 \mathrm{~g}$ of IBA hormone was dissolved in ethyl alcohol in order to dilute the solution mixed with distilled water to make the volume 1 litre; $1 \mathrm{~g}$ in 1 litre become $1000 \mathrm{ppm}$ which is made to be stock solutions. It was further diluted with $100 \mathrm{ml}$ using the equation: $\mathrm{V} 1 \mathrm{~S} 1=\mathrm{V} 2 \mathrm{~S} 2$

Where, $\mathrm{V} 1=$ Volume of the stock solution, $\mathrm{V} 2=$ Volume of the stock solution, S1= Concentration of the stock solution, S2= Concentration of the working solution. For $100 \mathrm{ppm}, 100 \mathrm{ml}$ stock solution was added in $900 \mathrm{ml}$ distilled water to become 1 litre of 100 ppm solution. For 200 ppm, $200 \mathrm{ml}$ stock solution was added in $800 \mathrm{ml}$ distil water to become 1 litre of 200 ppm solution. For 300 ppm, $300 \mathrm{ml}$ of stock solution was added in $700 \mathrm{ml}$ of distil to become the volume 1 litre of $300 \mathrm{ppm}$ solution. Simultaneously, instead of hormone; water was poured inside the hole to consider as control. 


\section{Observations recorded}

The observations of the sprouts and roots from the nodal region were recorded plot and sub-plot wise. Under the above ground parameter studies were made on length of leaf, breadth of leaf, leaf area, shoot fresh and dry weight and under the below ground parameter observations were recorded on no. of roots, root length, root fresh and dry weight.

Leaf length was measured with the help of a scale. It was the distance along the mid rib of the leaf from the tip of the leaf to the point of attachment of leaf lamina with the petiole. The unit of observation was in centimetres. Leaf breadth was measured with the help of a scale. It was the diameter of the largest possible circle that could be drawn on the leaf surface. It was recorded in centimetres. Leaf area was measured with the help of a leaf area meter. The collected samples were covered with wet tissue and polythene sheets to prevent desiccation during transport from the main field to the laboratory. They were kept pressed to keep the leaves flat. The data was recorded at last observation date (90 DAP) in square centimetres. The above ground part or the shoot region was separated and fresh weight was then taken using electronic balance and expressed in gram. The shoot portion was dried in a hot air oven maintained at $85 \pm 2{ }^{\circ} \mathrm{C}$ for $48 \mathrm{~h}$ and cooled in desiccators for $30 \mathrm{~min}$., weighed in electronic balance and expressed in gram.

Total no of roots was counted carefully and was recorded for all the sprouts at last observation date. The root length is measured from collar to the tip of taproot with the help of measuring scale and expressed in $\mathrm{cm}$. The underground part or the root portion was separated and weighed by using electronic balance and expressed in g. The root dry portion was separated and dried in a hot air oven maintained at $85 \pm 2^{\circ} \mathrm{C}$ for $48 \mathrm{~h}$ and cooled in desiccators for $30 \mathrm{~min}$., weighed in an electronic balance and expressed in gram.

Volume index (VI): Volume index is arrived by using the formula has been described by Manavalan, 1990 and expressed as below:

Volume index $(\mathrm{VI})=(\text { collar diameter })^{2} \mathrm{X}$ Height $(\mathrm{cm})$

Dickson Quality index: The quality index was calculated by using the formula described by Dickson et al., (1960) and expressed by the formula:

Dickson Quality Index (DQI) $=$ Total seedling dry weight $(\mathrm{g}) /[$ Height $(\mathrm{cm}) /$ diameter $(\mathrm{mm})]$ $+[$ (shoot dry weight $(\mathrm{g}) /$ Root dry weight $(\mathrm{g})]$

\section{Results and Discussion}

\section{Number of roots and root length}

Perusal of the result (Table 2) reveals that highly significant variations of number of roots of sprouts among 5 species and hormone doses among interactions is best observed in $B$. nutans (55.3) followed by B. vulgaris (19.0); B. tulda (10.3); B. bambos (7.7) and least in D. strictus (4.0). Behaviour of hormone is dependant at species $0 \mathrm{ppm}$ and $300 \mathrm{ppm}$ for $D$. strictus; $0 \mathrm{ppm}$ for $B$. vulgaris, B. nutans and D. strictus and 100 ppm for $B$. tulda whereas 0 ppm is best for $D$. strictus and least was observed in $100 \mathrm{ppm}$ for D. strictus, B. bambos and B. vulgaris; $300 \mathrm{ppm}$ for $B$. nutans and $200 \mathrm{ppm}$ for $B$. tulda.

Perusal of the result (Table 2) reveals that highly significant variations of root length of sprouts among 5 species and hormone doses among interactions is best observed in $B$. nutans $(36.7 \mathrm{~cm})$ followed by B. tulda $(22.7$ $\mathrm{cm})$; B.vulgaris $(17.3 \mathrm{~cm}) ;$ B. Bambus $(8.6$ 
$\mathrm{cm})$ and least in D. strictus $(3.6 \mathrm{~cm})$. Behaviour of hormone is dependant at species $200 \mathrm{ppm}$ and $300 \mathrm{ppm}$ for D. strictus; 0 ppm for B.vulgaris; $200 \mathrm{ppm}$ for B.nutans; $0 \mathrm{ppm}$ for $B$. tulda and B. bambos whereas $200 \mathrm{ppm}$ is best for $B$. nutans and least was with $0 \mathrm{ppm}$ in D. strictus and $300 \mathrm{ppm}$ in B. vulgaris, B. nutans, B.tulda and B.bambos.

\section{Fresh and Dry Shoot Biomass}

Perusal of the result (Table 4) reveals that highly significant variations of fresh shoots of the sprouts among 5 species and hormone doses among interactions is best observed in B. (170.06 g) followed by B. vulgaris (115.64 g); B. tulda (27.09 g); D. strictus (13.01 g) and least observed in B.bambos (2.91g). Behaviour of hormone is dependant at species 0 ppm for D. strictus, B.nutans and B. tulda; $100 \mathrm{ppm}$ for $B$. vulgaris and B. bambos, whereas $0 \mathrm{ppm}$ is best for $B$. nutans and least was observed in $300 \mathrm{ppm}$ for D. strictus and $B$. vulgaris; $100 \mathrm{ppm}$ for $B$. nutans and $B$. tulda and 200 ppm for B. bambos.

Table 3 reveals that highly significant variations of dry weight of shoots of sprouts among 5 species and hormone doses, among interactions is best observed in $B$. nutans $(86.77 \mathrm{~g})$ followed by $B$. vulgaris $(57.77 \mathrm{~g}) ; B$. tulda $(13.74 \mathrm{~g})$; D. strictus $(6.81 \mathrm{~g})$ and least observed in B.bambos (1.62 g). Behaviour of hormone is dependant at species $0 \mathrm{ppm}$ for $D$. strictus, B. nutans and B. tulda; $100 \mathrm{ppm}$ for $B$. vulgaris and $B$. bambos, whereas $0 \mathrm{ppm}$ is best for $B$. nutans and least was observed in $300 \mathrm{ppm}$ for D. strictus and B. vulgaris; 100 ppm for $B$. nutans; 200 ppm for $B$. tulda and 0 ppm and 200 ppm for B. bambos.(Fig: 3)

\section{Fresh and Dry Root Biomass}

Analysis of fresh below ground biomass data (Table 5) shows highly significant variations of fresh weight of roots of sprouts among 5 species and hormone doses among interactions is best observed in $B$. nutans $(21.5 \mathrm{~g})$ followed by $B$. tulda $(6.3 \mathrm{~g}) ; B$. vulgaris (6.25 g); D. strictus (1.55 g) and least observed in B. bambos (1.12 g). doses among interactions is best observed in $B$. nutans $(42.51 \mathrm{~g})$ followed by $B$. vulgaris (11.79 g); B. tulda (10.74 g); D. strictus (3.03 g) and least observed in B. bambos $(2.00 \mathrm{~g})$. Dry below ground biomass has no effect over species, hormone and interaction. Behaviour of hormone is dependant at species, the best hormone dose is $300 \mathrm{ppm}$ for $D$. strictus, $B$. nutans and B.bambos; $200 \mathrm{ppm}$ for $B$. vulgaris and0 ppm for B.tulda whereas 300 ppm is best for $B$. nutans and least was sprouts among 5 species and hormone at species $0 \mathrm{ppm}$ for $D$. strictus, $B$. vulgaris and B.tulda; 300 ppm for B. nutans and B.bambos whereas $300 \mathrm{ppm}$ is best for $B$. nutans and least was observed in $200 \mathrm{ppm}$ for $D$. strictus and B. bambos; $300 \mathrm{ppm}$ for B. vulgaris and $100 \mathrm{ppm}$ for $B$. nutans and B. tulda. observed in 200 ppm for D. strictus and B. bambos.; 300 ppm for B. vulgaris and B. tulda and 100 ppm for B. nutans.

\section{Leaf Area}

Interpretation of leaf area (Table 3) shows highly significant variations among 5 species and hormone doses among interactions is best observed strictus; 200 ppm for B. vulgaris and B. nutans; 0 ppm for B. bambos and $100 \mathrm{ppm}$ for $B$. tulda whereas $200 \mathrm{ppm}$ is best for $B$. vulgaris and least was observed in $200 \mathrm{ppm}$ for D. strictus and $300 \mathrm{ppm}$ for $B$. vulgaris, B. tulda and $B$. bambos and 0 ppm for $B$. nutans.in $B$. vulgaris $(36.0$ sq. $\mathrm{cm}$ ) followed by $B$. nutans (35.8 sq. cm); D. strictus (18.5 sq. cm); B. tulda $(15.8$ sq. $\mathrm{cm})$ and least observed in $B$. bambos $(7.4$ sq. $\mathrm{cm})$. Behaviour of hormone is dependant at species $300 \mathrm{ppm}$ for D. strictus and 300 ppm for B. vulgaris, B. tulda and B. bambos and 0 ppm for $B$. nutans. 


\section{Quality Index and Volume Index}

In Perusal of data Table 6. regarding quality Index of regenerations of bsamboo species revealed significant variations among all the 5 species, among 4 IBA hormone doses and among its interaction with species. Interactions of all species with IBA doses was best observed in $B$. nutans (6.22) followed by B. vulgaris (3.09), B. tulda (1.69), and D. strictus (0.42) and minimum in B. bambos (0.22). 0 ppm was observed to be best response0 ppm was observed to be best responsive for $B$. nutans, $D$. strictus, $B$. vulgaris and $B$. tulda whereas $100 \mathrm{ppm}$ was observed to be best responsive for $B$. bambos. Among all the interactions between species and IBA concentrations, maximum Quality Index was observed in $B$. nutans for $100 \mathrm{ppm}$ (7.8) and minimum in B. bambos for $0 \mathrm{ppm}$, $200 \mathrm{ppm}$ and $300 \mathrm{ppm}$ and D. strictus for 300 ppm.
Interpretation of Volume Index in Table 7 depicts that all the 5 species with respect to their response towards 4 concentrations of IBA was observed to be significant. Significant variation was also observed among all the interactions of species with doses of IBA. However, Volume Index regarding the behaviour of different doses of IBA and its effect was observed to be nonsignificant. Maximum Volume Index was observed in B. vulgaris (1593.13) followed by $B$. nutans (716.59), B. tulda (633.76), B. bambos (423.74) and minimum in D. strictus (240.38). With respect to most effective dose of IBA; $300 \mathrm{ppm}$ was observed to best responding in $D$. strictus, $B$. vulgaris, $B$. nutans and $B$. tulda whereas $200 \mathrm{ppm}$ was observed to be best responding in B. bambos. Among all the interactions, maximum Volume Index was observed in B. vulgaris for $200 \mathrm{ppm}$ (2442.8) and minimum in D. strictus for $100 \mathrm{ppm}(192.8)$.

Table.1 Experimental Layout of split plot design with 4 hormone doses (B1, B2 B3 and B4) as sub-plot treatments and 5 bamboo species as 5 main plot treatments A1, A2, A3, A4 and A5,

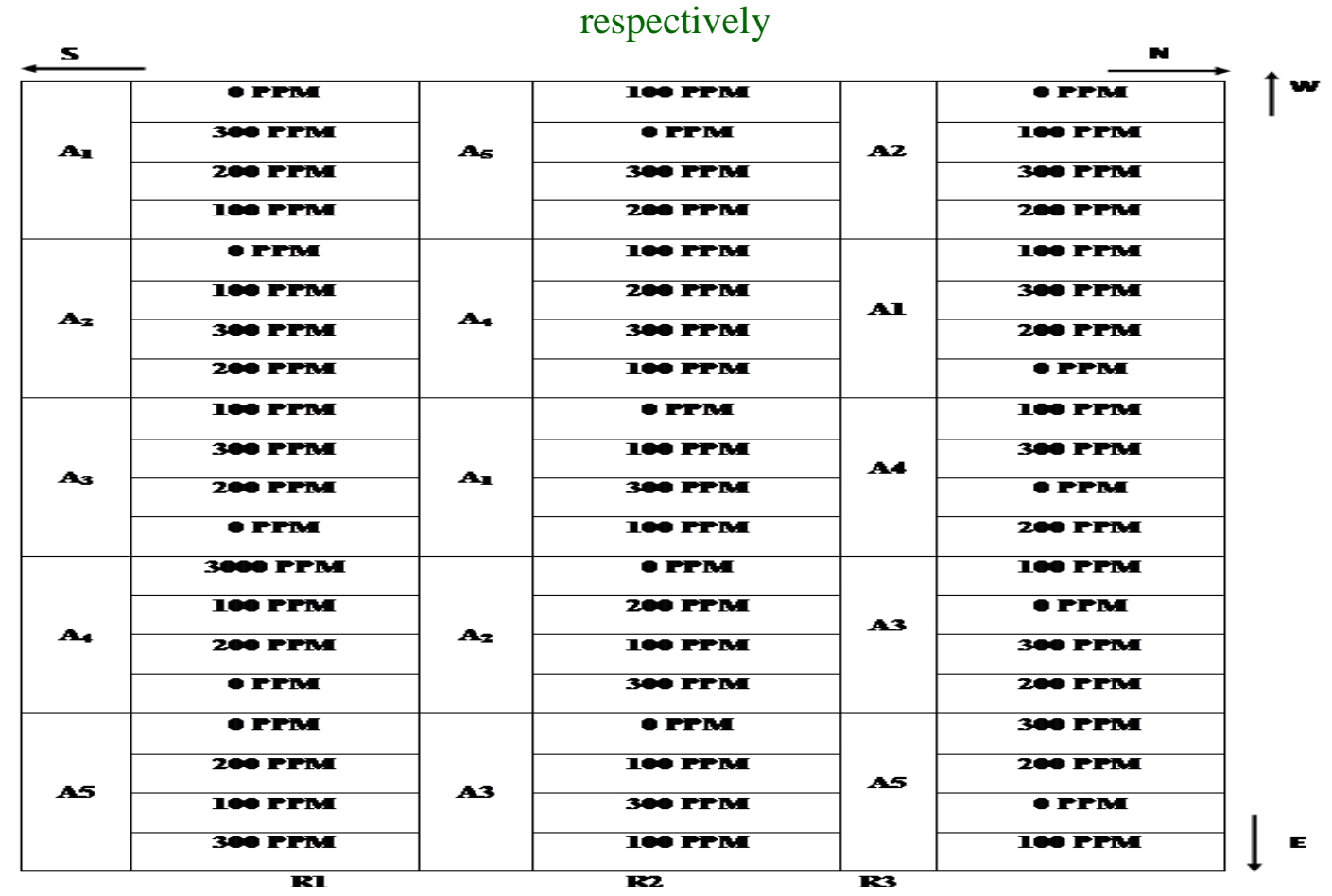


Table.2 Length and number of roots developed after 3 months of planting of clones treated with different concentrations of IBA of various bamboo species in coastal Odisha

\begin{tabular}{|c|c|c|c|c|c|c|c|c|c|c|}
\hline & \multicolumn{5}{|c|}{ Root Length (cm) } & \multicolumn{5}{|c|}{ Number of roots } \\
\hline & B1 & B2 & B3 & B4 & Mean & B1 & B2 & B3 & B4 & Mean \\
\hline A1 & 2.5 & 2.6 & 3.2 & 3.2 & 2.86 & 4.0 & 3.0 & 3.7 & 4.0 & 3.67 \\
\hline A2 & 17.3 & 14.0 & 13.6 & 11.8 & 14.18 & 19.0 & 7.3 & 14.7 & 16.0 & 14.25 \\
\hline A3 & 36.5 & 35.9 & 36.7 & 26.3 & 33.84 & 55.3 & 38.3 & 27.3 & 25.3 & 36.58 \\
\hline A4 & 22.7 & 7.3 & 6.3 & 5.1 & 10.37 & 9.0 & 10.3 & 4.0 & 5.0 & 7.08 \\
\hline A5 & 8.6 & 4.9 & 7.0 & 2.2 & 5.68 & 7.7 & 4.0 & 2.7 & 3.7 & 4.50 \\
\hline Mean & 17.51 & 12.92 & 13.37 & 9.73 & & 19.00 & 12.60 & 10.47 & 10.80 & \\
\hline Comparisons & \multicolumn{2}{|l|}{$\mathbf{S E}_{\mathbf{d}}$} & \multicolumn{2}{|c|}{$\mathrm{CD}_{0.01}$} & Remarks & SEd & \multicolumn{2}{|c|}{$\mathrm{CD}_{0.05}$} & $\mathrm{CD}_{0.01}$ & Remarks \\
\hline $\mathbf{A}$ & \multicolumn{2}{|l|}{0.51} & \multicolumn{2}{|c|}{1.70} & $* *$ & 0.78 & \multicolumn{2}{|c|}{1.81} & 2.63 & $* *$ \\
\hline B & \multicolumn{2}{|l|}{1.30} & \multicolumn{2}{|c|}{3.58} & $* *$ & 1.33 & \multicolumn{2}{|c|}{2.71} & 3.65 & $* *$ \\
\hline$A \times B$ & \multicolumn{2}{|l|}{0.58} & \multicolumn{2}{|c|}{1.60} & $* *$ & 0.59 & \multicolumn{2}{|c|}{1.21} & & $* *$ \\
\hline
\end{tabular}

A1, A2, A3, A4 and A5 re[resent various bamboo species studied namely, Dendrocalamus strictus, Bambusa vulgaris, Bambusa nutans, Bambusa tulda and Bambusa bambos, respectively, B1, B2, B3, B4 represent different hormone doses i.e., 0 ppm, $100 \mathrm{ppm}, 200 \mathrm{ppm}$ and $300 \mathrm{ppm}$, respectively and $*$ and $* *$ represent significant and $5 \%$ level of significance and significant at $1 \%$ level of significance, respectively.

Table.3 Leaf area of sprouts developed after 3 months of planting of clones treated with different concentrations of IBA of various bamboo species in coastal Odisha

\begin{tabular}{|c|c|c|c|c|c|}
\hline & \multicolumn{5}{|c|}{ Leaf Area $\left(\mathrm{cm}^{2}\right)$} \\
\hline & B1 & B2 & B3 & B4 & Mean \\
\hline A1 & 15.6 & 17.3 & 14.9 & 18.5 & 16.57 \\
\hline A2 & 28.2 & 32.1 & 36.0 & 28.1 & 31.10 \\
\hline A3 & 17.4 & 26.7 & 35.8 & 26.2 & 26.53 \\
\hline A4 & 14.0 & 15.8 & 7.0 & 5.5 & 10.57 \\
\hline A5 & 7.4 & 4.9 & 5.0 & 2.6 & 4.98 \\
\hline Mean & 16.52 & 19.35 & 19.73 & 16.20 & \multirow[b]{2}{*}{ Remarks } \\
\hline \multicolumn{2}{|l|}{ Comparisons } & \multicolumn{2}{|c|}{$\mathrm{CD}_{0.05}$} & $\mathrm{CD}_{0.01}$ & \\
\hline A & 1.91 & \multicolumn{2}{|c|}{4.41} & 6.42 & $* *$ \\
\hline B & 3.09 & \multicolumn{2}{|c|}{6.32} & 8.51 & $*$ \\
\hline$A \times B$ & 1.38 & \multicolumn{2}{|c|}{2.83} & 3.80 & $* *$ \\
\hline
\end{tabular}

A1, A2, A3, A4 and A5 re[resentvarious bamboo species studied namely, Dendrocalamus strictus, Bambusa vulgaris, Bambusa nutans, Bambusa tulda and Bambusa bambos, respectively,B1, B2, B3, B4 represent different hormone doses i.e., $0 \mathrm{ppm}, 100 \mathrm{ppm}, 200 \mathrm{ppm}$ and $300 \mathrm{ppm}$, respectively and $*$ and $* *$ represent significant and $5 \%$ level of significance and significant at $1 \%$ level of significance, respectively. 
Table.4 Fresh/ dry biomass of shoots(sprouts)developed after 3 months of planting of clones treated with different concentrations of IBA of various bamboo species in coastal Odisha

\begin{tabular}{|c|c|c|c|c|c|c|c|c|c|c|}
\hline & \multicolumn{5}{|c|}{ Fresh above ground biomass (g) } & \multicolumn{5}{|c|}{ Dry above ground biomass (g) } \\
\hline & B1 & B2 & B3 & B4 & Mean & B1 & B2 & B3 & B4 & Mean \\
\hline A1 & 25.5 & 13.3 & 8.3 & 4.9 & 13.01 & 12.6 & 6.7 & 4.3 & 2.6 & 6.81 \\
\hline A2 & 119.8 & 144.0 & 131.9 & 66.9 & 115.64 & 59.2 & 71.2 & 65.3 & 35.4 & 57.77 \\
\hline A3 & 275.1 & 117.3 & 147.3 & 140.7 & 170.06 & 142.2 & 57.3 & 75.1 & 72.1 & 86.67 \\
\hline A4 & 44.3 & 18.1 & 22.4 & 23.6 & 27.09 & 23.5 & 19.9 & 10.2 & 11.4 & 13.74 \\
\hline A5 & 2.5 & 4.4 & 2.1 & 2.7 & 2.91 & 1.3 & 2.3 & 1.3 & 1.6 & 1.62 \\
\hline Mean & 93.44 & 59.39 & 62.40 & 47.74 & & 47.76 & 31.48 & 31.24 & 24.62 & \\
\hline Comparisons & $\mathbf{S E}_{\mathrm{d}}$ & \multicolumn{2}{|c|}{$\mathrm{CD}_{0.05}$} & $\mathrm{CD}_{0.01}$ & Remarks & $\mathbf{S E}_{\mathbf{d}}$ & \multicolumn{2}{|c|}{$\mathrm{CD}_{0.05}$} & $\mathrm{CD}_{0.01}$ & Remarks \\
\hline A & 0.74 & \multicolumn{2}{|c|}{1.71} & 2.48 & $* *$ & 0.74 & \multicolumn{2}{|c|}{1.70} & 2.47 & $* *$ \\
\hline B & 1.63 & \multicolumn{2}{|c|}{3.33} & 4.49 & $* *$ & 2.15 & \multicolumn{2}{|c|}{4.39} & 5.91 & $* *$ \\
\hline$A \times B$ & 0.73 & \multicolumn{2}{|c|}{1.49} & 2.01 & $* *$ & 0.96 & \multicolumn{2}{|c|}{1.96} & 2.64 & $* *$ \\
\hline
\end{tabular}

A1, A2, A3, A4 and A5 re[resent various bamboo species studied namely, Dendrocalamus strictus, Bambusa vulgaris, Bambusa nutans, Bambusa tulda and Bambusa bambos, respectively, B1, B2, B3, B4 represent different hormone doses i.e., 0 ppm, 100 ppm, $200 \mathrm{ppm}$ and $300 \mathrm{ppm}$, respectively and $*$ and $* *$ represent significant and $5 \%$ level of significance and significant at $1 \%$ level of significance, respectively.

Table.5 Fresh/dry biomass of rootsdeveloped after 3 months of planting of clones treated with different concentrations of IBA of various bamboo species in coastal Odisha

\begin{tabular}{|c|c|c|c|c|c|c|c|c|c|c|}
\hline & \multicolumn{5}{|c|}{ Fresh below ground biomass (g) } & \multicolumn{5}{|c|}{ Dry below ground biomass (g) } \\
\hline & B1 & B2 & B3 & B4 & Mean & B1 & B2 & B3 & B4 & Mean \\
\hline A1 & 3.5 & 3.2 & 2.0 & 3.4 & 3.03 & 1.7 & 1.6 & 1.1 & 1.8 & 1.55 \\
\hline A2 & 14.4 & 13.9 & 13.4 & 5.5 & 11.79 & 7.3 & 7.0 & 7.4 & 3.3 & 6.25 \\
\hline A3 & 41.8 & 29.7 & 44.2 & 54.4 & 42.51 & 21.6 & 14.5 & 23.3 & 26.6 & 21.5 \\
\hline A4 & 13.0 & 12.5 & 9.7 & 7.7 & 10.74 & 7.8 & 7.1 & 5.4 & 4.9 & 6.3 \\
\hline A5 & 1.8 & 2.0 & 1.6 & 2.6 & 2.00 & 1.0 & 1.1 & 0.9 & 1.5 & 1.12 \\
\hline Mean & 14.89 & 12.26 & 14.18 & 14.73 & & 7.88 & 6.26 & 7.62 & 7.62 & \\
\hline Comparisons & $\mathbf{S E}_{\mathrm{d}}$ & \multicolumn{2}{|c|}{$\mathrm{CD}_{0.05}$} & $\mathrm{CD}_{0.01}$ & Remarks & $\mathbf{S E}_{\mathbf{d}}$ & \multicolumn{2}{|l|}{$\mathrm{CD}_{0.05}$} & $\mathrm{CD}_{0.01}$ & Remarks \\
\hline A & 0.25 & \multicolumn{2}{|c|}{0.57} & 0.83 & $* *$ & 0.56 & \multicolumn{2}{|l|}{1.30} & 1.89 & NS \\
\hline $\mathrm{B}$ & 1.22 & \multicolumn{2}{|c|}{2.49} & 3.36 & $* *$ & 0.65 & \multirow{2}{*}{\multicolumn{2}{|c|}{$\begin{array}{l}1.33 \\
0.50\end{array}$}} & 1.79 & NS \\
\hline$A \times B$ & 0.55 & \multicolumn{2}{|c|}{1.12} & 1.50 & $* *$ & 0.29 & & 0.59 & & NS \\
\hline
\end{tabular}

A1, A2, A3, A4 and A5 re[resent various bamboo species studied namely, Dendrocalamus strictus, Bambusa vulgaris, Bambusa nutans, Bambusa tulda and Bambusa bambos, respectively, B1, B2, B3, B4 represent different hormone doses i.e., 0 ppm, $100 \mathrm{ppm}, 200 \mathrm{ppm}$ and $300 \mathrm{ppm}$, respectively and $*$ and $* *$ represent significant and $5 \%$ level of significance and significant at $1 \%$ level of significance, respectively. 
Table.6 Dickson Quality Index of regeneration developed after 3 months of planting of clones treated with different concentrations of IBA of various bamboo species in coastal Odisha

\begin{tabular}{|c|c|c|c|c|c|}
\hline & B1 & B2 & B3 & B4 & Mean \\
\hline A1 & 0.7 & 0.4 & 0.3 & 0.2 & 0.42 \\
\hline A2 & 3.9 & 3.4 & 3.4 & 1.6 & 3.09 \\
\hline A3 & 7.8 & 4.4 & 5.6 & 7.1 & 6.22 \\
\hline $\mathbf{A 4}$ & 2.5 & 2.3 & 0.9 & 1.2 & 1.69 \\
\hline A5 & 0.2 & 0.3 & 0.2 & 0.2 & 0.22 \\
\hline Mean & 3.01 & 2.16 & 2.09 & 2.06 & 2.33 \\
\hline Comparisons & \multicolumn{2}{|l|}{$\mathbf{S E}_{\mathrm{d}}$} & $\mathrm{CD}_{0.05}$ & $\mathrm{CD}_{0.01}$ & Remarks \\
\hline $\mathbf{A}$ & \multicolumn{2}{|l|}{0.40} & 0.92 & 1.34 & $* *$ \\
\hline $\mathbf{B}$ & \multicolumn{2}{|l|}{0.22} & 0.44 & 0.60 & $* *$ \\
\hline$A \times B$ & 0.10 & \multicolumn{2}{|c|}{0.20} & & $* *$ \\
\hline
\end{tabular}

A1, A2, A3, A4 and A5 re[resent various bamboo species studied namely, Dendrocalamus strictus, Bambusa vulgaris, Bambusa nutans, Bambusa tulda and Bambusa bambos, respectively, B1, B2, B3, B4 represent different hormone doses i.e., 0 ppm, $100 \mathrm{ppm}, 200 \mathrm{ppm}$ and $300 \mathrm{ppm}$, respectively and * and ** represent significant and 5\% level of significance and significant at $1 \%$ level of significance, respectively.

Table.7 Volume Index of regeneration developed after 3 months of planting of clones treated with different concentrations of IBA of various bamboo species in coastal Odisha

\begin{tabular}{|c|c|c|c|c|c|}
\hline & B1 & B2 & B3 & B4 & Mean \\
\hline A1 & 268.7 & 192.8 & 150.7 & 349.3 & 240.38 \\
\hline A2 & 1444.7 & 2442.8 & 1069.2 & 1416.0 & 1593.19 \\
\hline A3 & 687.5 & 655.4 & 487.8 & 1035.6 & 716.59 \\
\hline A4 & 534.8 & 472.5 & 610.9 & 916.8 & 633.76 \\
\hline A5 & 338.6 & 468.4 & 521.0 & 367.0 & 423.74 \\
\hline Mean & 654.86 & 846.37 & 567.92 & 816.96 & 721.53 \\
\hline Comparisons & \multicolumn{2}{|l|}{$\mathbf{S E}_{\mathrm{d}}$} & $\mathbf{C D}_{0.05}$ & $\mathrm{CD}_{0.01}$ & Remarks \\
\hline $\mathbf{A}$ & \multicolumn{2}{|l|}{110.99} & 255.95 & 372.38 & $* *$ \\
\hline B & \multicolumn{2}{|l|}{263.59} & - & - & NS \\
\hline$A \times B$ & 117.88 & \multicolumn{2}{|c|}{240.71} & - & $*$ \\
\hline
\end{tabular}

A1, A2, A3, A4 and A5 re[resent various bamboo species studied namely, Dendrocalamus strictus, Bambusa vulgaris, Bambusa nutans, Bambusa tulda and Bambusa bambos, respectively, B1, B2, B3, B4 represent different hormone doses i.e., $0 \mathrm{ppm}, 100 \mathrm{ppm}, 200 \mathrm{ppm}$ and $300 \mathrm{ppm}$, respectively and * and ** represent significant and 5\% level of significance and significant at $1 \%$ level of significance, respectively. 


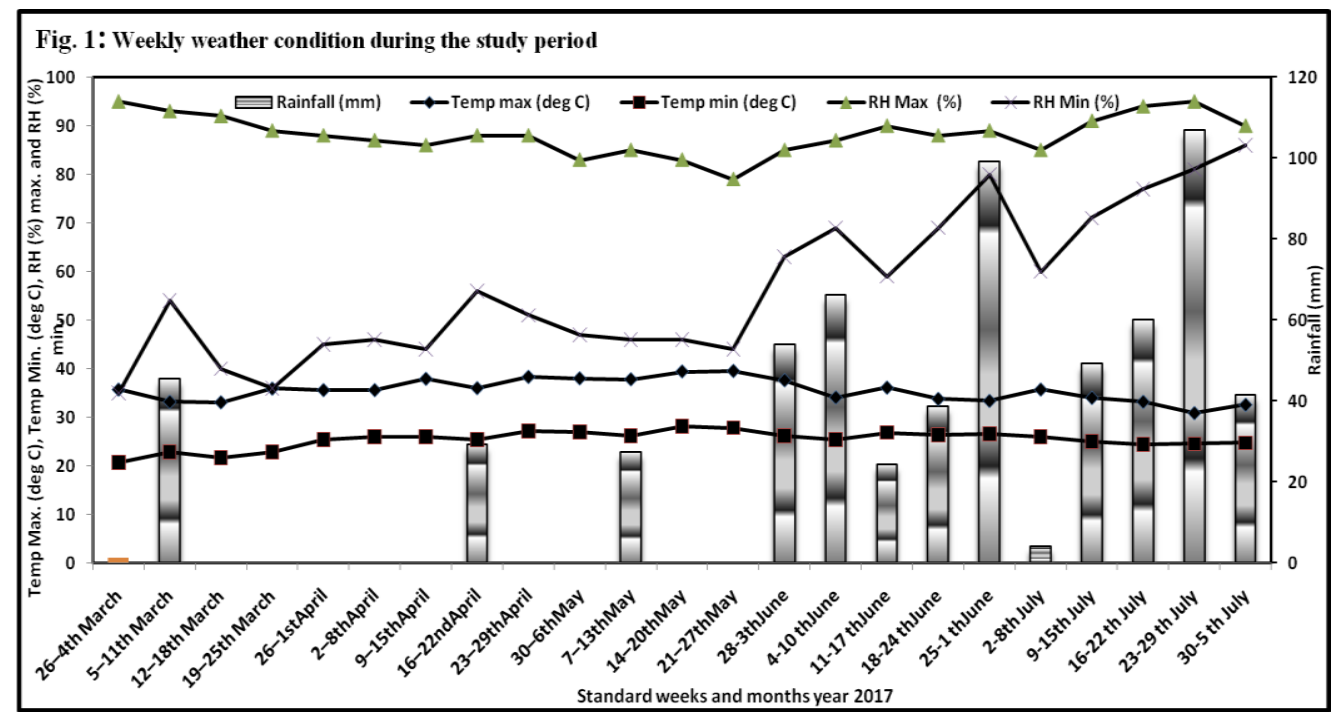

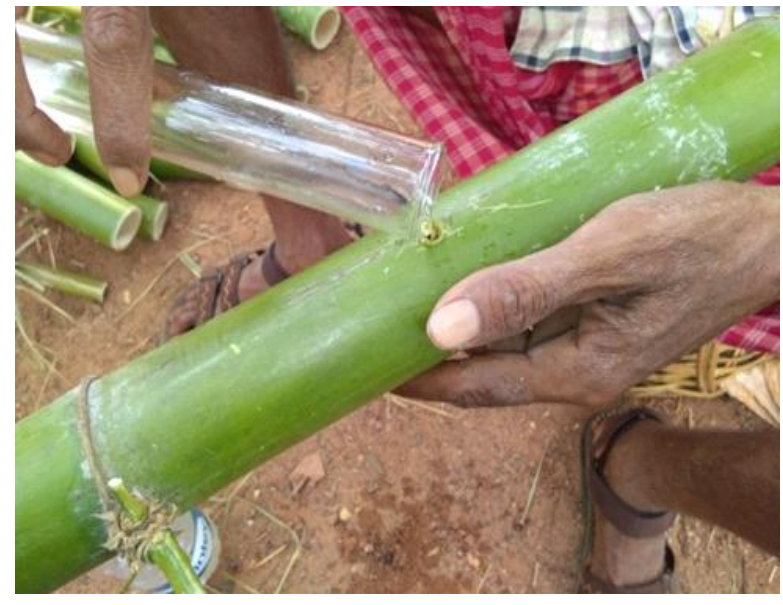

Fig.2 Pouring hormone solution through the holes

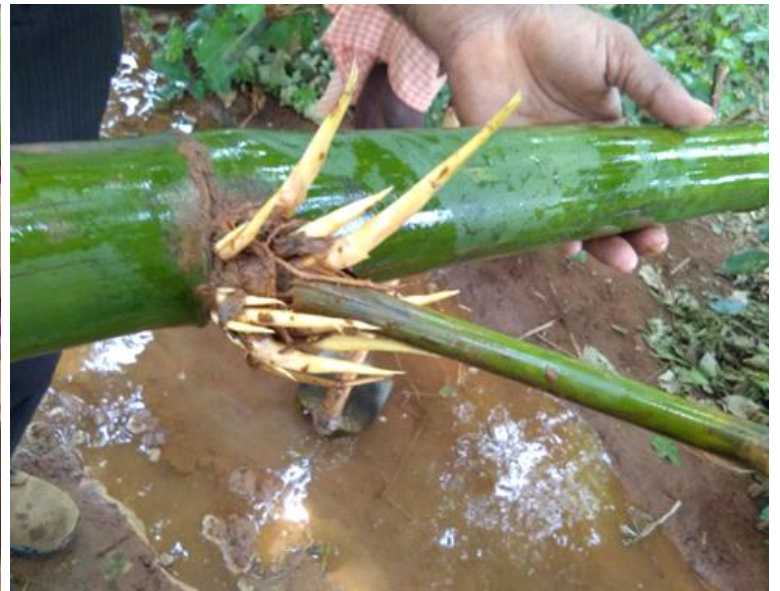

Fig.3 Emergence of 1st sprout in Bambusa tulda
Sprouting and rooting behaviour of cuttings primarily depends on genotypic characteristics, environmental factors and the interaction between them (Dubey et al., 2008). Variation in sprouting and rooting behaviour in different bamboo species during the present study may be attributed to difference in genotypic characters (Saharia et al., 1990, Banik, 1984). Poor rooting ability in B. nutans and D. giganteus was also reported in earlier studies (Gulabrao et al., 2011; Kaushal et al., 2009).Variations was also found among the treatments. number of roots per cutting were noticed in the cuttings treated with IBA $500 \mathrm{ppm}$ in rainy season while, minimum (3.10) number of roots was observed in the cuttings treated with NAA $200 \mathrm{ppm}$ treated cuttings in Bambusa nagalandiana (Naithani). Season or period of collection of cuttings also plays a major influence on the rooting (Dore 1953; Nanda et al., 1968; Hartmann et al., 1997). Nanda et al., (1975) attributed seasonal variations in rooting response to the changes in the relative/ absolute levels of endogenous rooting inhibitors and promoters. Further, in this study, higher rooting percentage in summer was attributed to higher temperature with high humidity as the cuttings were regularly irrigated. Agnihotri and Ansari 
(2000) also observed adventitious rhizogenesis in $B$. vulgaris and D. strictus during high temperature and long photoperiod. In present study, fungal infections were observed on $D$. giganteus which resulted in high mortality of the sprouts even after rooting of the cuttings. In this study fungal infections were being observed in species $B$. tulda and in some species of $B$. nutans. Kaushal and Tewari (2009) also reported poor survival rate of cuttings in $D$. giganteus due to fungal infection. Season plays an important role in the physiological state of the parent plant and the cuttings (Hartmann et al., 1997; Singh, 2006).

\section{Acknowledgement}

The authors are grateful to Prof K. K. Rout, Dean College of Forestry and Prof M. M. Hossain, Ex-Dean, College of Forestry, O.U.A.T., Bhubaneswar for their facilitation and support and field staff of this College for their untiring contribution to make this research successful.

\section{References}

Agnihotri, K. Ansari, S. A. 2000. Adventitious rhizogenesis in relation to seasonal variation, size of culm branch cuttings and IAA treatment in bamboos. Indian Forester 126: 971-984.

Banik, R. L.2008. Issues in production of bamboo planting materials-lessons and strategies. Indian Forester 134(3): 291-304.

Banik, R. L. 1984. Macro-propagation of bamboos by pre-rooted and prerhizomed branch cuttings. Bana Biggyan Patrika 3(1/2): 67-73.

Banik, R. L. 2000. Silviculture and Field Guide to Priority Bamboos of Bangladesh and South Asia. Chittagong: Publication of Bangladesh Forest Research Institute, P. 187.
Dickson, A., Leaf, A. L., and Hosner, J.F. 1960.Quality appraisal of white spruce and white pine seedling stock in nurseries. Forestry Chronicle, Ottawa, Vol. 36, Pp. 10- 13.

Dore, J.1953. Seasonal variations in the regeneration of root cuttings. Nature 172: 189.

Dubey, R. M., Das P. S., Choudhary, R. 2008. An investigation into macroproliferation of some selected bamboo species of Assam. Indian Forester 134(3): 367-37

Gulabrao, Y.A., Kaushal, R., Suresh, N.V, Verma, A, and Singh, R. 2011. Effect of IBA on rooting of bamboo species. Indian Journal of Ecology, 38: 227-228

Haridasan, K., Tewari, S. 2008. Bamboo for Pan India programmes-preliminary observations from recent trials. Indian Forester 134(3): 314-324.

Haridasan, K., Tewari, S. 2008. Bamboo for Pan India programmes-preliminary observations from recent trials. Indian Forester134(3): 314-324

Hartmann, T, Kester, D, Davies, R. L.1997. Plant Propagation: Principles and Practices. New Delhi: Hall Press, Pp. 276-391.

Kaushal, R., Tewari, S. 2009. Technology for Vegetative Propagation of Bam-boos. Research Bulletin No. 166., G.B. Pant University of Agriculture \&Technology, Uttarakhand, India. P. 22.

Manavalan, A. 1990. Seedling vigour and bioproductivity inwoody biomass species. Ph.D. Thesis, Madurai Kamaraj University, Madurai.

Naithani, H.B., Biswas, S. 1992. Gregarious flowering of Dendrocalamusmembranaceus. Indian Forester118: 300-301.

Nanda K. K., Purohit, A. N., Adarsh, B. and Anand, V. K. 1968. Seasonal rooting response of stem cuttings of some forest tree species to auxins. Indian Forester 
94: 154-162.

Nanda K. K. 1975. Physiology of adventitious root formation. Indian. Journal of Plant Physiology, 18: 80-89.

Pattanaik, S., Das, P., Borah, E. andKaur, K. 2004. Vegetative multiplication of BambusabalcooaRoxb. using branch cuttings. Journal of Bamboo and Rattan, 4: 365-374.

Saharia, U. K., Sen, S. K. 1990. Optimum age bamboo culms for nodal cuttings. Indian Forester116(10): 780-784
Seethalakshmi, K. K., Kumar, M. S. M. 1998. Bamboos of India. Peechi, Kerala, India. Technical Bulletin of Kerala Forest Research Institute, P. 342.

Singh, S., Nain, NP. S., Meena, S. L. And Tripathi S. P. 2006. Patterns of adventitious root induction during different seasons in some bamboo species. Journal of Bamboo and Rattan 5(1\&2): 89-95.

\section{How to cite this article:}

Sahoo, S., R. K. Kar and Mohanty, T. L. 2020. Effect of Plant Growth Hormones on Sprouting and Rooting Behaviour of Clones of Various Bamboo Species in coastal Odisha. Int.J.Curr.Microbiol.App.Sci. 9(07): 3521-3532. doi: https://doi.org/10.20546/ijcmas.2020.907.411 